\title{
The Role of GSK3 $\beta$ in T Lymphocytes in the Tumor Microenvironment
}

\author{
Anastasios Dimou ${ }^{1 *}$ and Konstantinos N. Syrigos ${ }^{2}$ \\ ${ }^{1}$ Division of Medical Oncology, Mayo Clinic, Rochester, MN, United States, ${ }^{2}$ Division of Medical Oncology, Third Department \\ of Medicine, University of Athens, Athens, Greece
}

Immunotherapy options for patients with cancer have emerged following decades of research on immune responses against tumors. Most treatments in this category harness T cells with specificity for tumor associated antigens, neoantigens, and cancer-testis antigens. GSK3 $\beta$ is a serine-threonine kinase with the highest number of substrates and multifaceted roles in cell function including immune cells. Importantly, inhibitors of GSK3 $\beta$ are available for clinical and research use. Here, we review the possible role of GSK3 $\beta$ in the immune tumor microenvironment, with goal to guide future research that tests GSK3 $\beta$ inhibition as an immunotherapy adjunct.

Keywords: GSK3 $\beta$, Tregs, IL-10, NFAT2, PD-L1

\section{OPEN ACCESS}

Edited by:

Fabrizio Mattei,

Istituto Superiore di Sanità (ISS), Italy

Reviewed by:

Guilan Shi,

University of South Florida,

United States

Robert J. Canter,

University of California, Davis,

United States

*Correspondence:

Anastasios Dimou

dimou.anastasios@mayo.edu

Specialty section:

This article was submitted to Cancer Immunity and Immunotherapy,

a section of the journal

Frontiers in Oncology

Received: 29 September 2019

Accepted: 15 June 2020

Published: 24 July 2020

Citation:

Dimou A and Syrigos KN (2020) The

Role of GSK3 $\beta$ in T Lymphocytes in

the Tumor Microenvironment.

Front. Oncol. 10:1221.

doi: 10.3389/fonc.2020.01221

\section{INTRODUCTION}

It is a truism that non-synonymous mutations bear the potential to generate neoantigens and elicit immune reactions against tumors (1). Therefore, development of established tumors requires evasion of host immune defenses (2). Further, the complex interaction between the immune system and the tumor takes the steps of elimination, equilibrium, and escape successively and largely reflects tumor evolution under the selective pressure of immunosurveillance $(3,4)$. Immune evasion is multifaceted and currently considered one of the hallmarks of cancer. The presence of immune infiltrates in the microenvironment of tumors is highly relevant from a therapeutic perspective, illustrated by multiple approvals of drugs which exert anti-cancer activity by harnessing the immune system across tumor types.

The main arms of immunity are the innate and adaptive responses against pathogens. The former is a faster type of response, does not require priming and does not exert target specificity which are all features of adaptive immunity (5). Innate immunity depends mostly on natural killer cells (NK cells), dendritic cells, macrophages and polymorphonuclear (PMN) cells. These, recognize pathogen-associated molecular patterns (PAMPs) and damage-associated molecular patterns (DAMPs) (6). PAMPs are pathogen derived and DAMPs are associated with injury and inflammation. Conversely, the cell types that orchestrate adaptive immunity are mainly the B and $\mathrm{T}$ lymphocytes. It is noteworthy that for both innate and adaptive responses, several cell types might adopt an immunosuppressive role in a context dependent manner, as is often the case with neutrophils (7), macrophages (8), and T regulatory cells (Tregs) in cancer (9).

In the tumor microenvironment, the main lymphocyte populations include either CD4 or CD8 positive cells. The former, use their T cell receptor (TCR) to recognize peptides bound to human leucocyte antigen (HLA) class II in the cell surface of antigen presenting and tumor cells, whereas the latter recognize peptides bound to HLA class I molecules in the plasma membrane of tumor cells. CD4 positive, or "helper" T lymphocytes (Th) further divide into Th1, Th2, and Th17 subgroups under the influence of cytokine and chemokine cues (10). Their main role is to prime B lymphocyte activation $(11,12)$ and antigen presentation to CD8+ cells $(13)$ whereas they can 
also function as cytotoxic $\mathrm{T}$ lymphocytes (CTLs) (14). Conversely, CD8 positive $\mathrm{T}$ lymphocytes mainly function as CTLs. Finally, Tregs can either develop independently as natural Tregs (nTregs) or emerge from CD4 positive T cells, as inducible Tregs (iTregs).

In a broad schema, the cytotoxic $\mathrm{T}$ lymphocytes (CTLs) can either be excluded from the tumor core ("cold" tumors), infiltrate the tumor core ("hot" tumors), or finally form immune aggregates that resemble secondary lymphoid organs (15). In the first scenario, an immunosuppressive microenvironment prevents the CTLs entry in the tumor core. In "hot" tumors, immune check points like the PD1-PDL1 axis play a central role in immune evasion. Finally, this system is highly regulated by interplay between cancer related mutations, the cytokine and chemokine milieu and importantly activation of molecular pathways in the adaptive immune system cells.

Glycogen Synthase Kinase $3 \beta$ (GSK3 $\beta$ ) is a serine threonine kinase with multiple substrates that was originally described for its role in the synthesis and storage of glycogen in skeletal muscle (16). Lithium, a GSK3 $\beta$ inhibitor, has been used for decades for the treatment of bipolar disorder (17). More recently, GSK $3 \beta$ is studied as a promising target for anti-cancer treatment with supporting preclinical data in a number of malignancies, including pancreatic cancer, colon cancer, bladder cancer, kidney cancer, and melanoma (18). GSK3 $\beta$ is very rarely altered at the genomic level in cancers, therefore pharmaceutical inhibition of GSK3 $\beta$ is not expected to be specific for cancer cells. With clinical trials of GSK3 $\beta$ inhibitors under way in the phase I space, an important question moving forward is the clinical effect of these drugs on cell types other than the cancer cells. Importantly, a growing body of literature shows that GSK3 $\beta$ inhibitors modulate the immune system in autoimmune and neoplastic disease contexts.

The seminal finding that GSK3 beta controls PDL1 levels indicates a possible effect of GSK3 beta inhibition on the immune reaction against tumors (19). Herein, we shall review the preclinical data on the effects of GSK3 beta inhibition in the tumor immune microenvironment with focus on $\mathrm{T}$ lymphocytes related adaptive immunity.

\section{DESCRIPTION OF THE GSK3 $\beta$ FUNCTION}

GSK3 beta is a master serine/threonine kinase in the cell with more substrates than any other kinase (20). It was originally described to phosphorylate and inactivate glycogen synthase in skeletal muscle, an effect reversed by insulin $(21,22)$. Insulin and other growth factors, bind to cognate receptors and activate AKT which then phosphorylates GSK3 $\beta$ at Ser9 (23). Phosphorylation at this site inhibits GSK3 $\beta$ which adopts a "closed" inactive structure (24). Alternatively, G-protein coupled receptors raise the levels of cyclic AMP and activate protein kinase A which interacts with GSK $3 \beta$ and induces the inhibitory phosphorylation at Ser9 (25). Additionally, GSK3 $\beta$ has been studied as a negative regulator of the WNT pathway as it phosphorylates and induces degradation of beta catenin $(23,26)$. GSK $3 \alpha$ is a significant isoform with overlapping but also some distinct functions (27). The GSK3 $\beta$ mode of function is unique among other kinases because it requires phosphorylation priming of the substrate at a serine or threonine position 4 amino-acids away from the GSK3 $\beta$ serine/threonine phosphorylation site, toward the carboxylic terminus of the substrate (28). Among the most studied substrates of GSK3 $\beta$ are the phosphatase and tensin homolog (PTEN) (29), cAMP responsive element binding protein (CREB) (20), beta catenin (26), and the nuclear factor of activated T cells (NFAT) (20). Figure 1 describes the main functions of GSK3 $\beta$ in the context of the WNT and the insulin receptor pathways.

\section{EFFECTS OF LITHIUM ON LYMPHOCYTES}

Lithium is a GSK3 $\beta$ inhibitor that has been used for a long time in the treatment of patients with bipolar disorder. It is known from early studies that lithium decreases peripheral lymphocyte count and in reverse, increases the peripheral neutrophil count in patients (30). The thymus of mice treated with lithium chloride has smaller size and decreased cellularity related to loss of $\mathrm{T}$ lymphocytes (31). In vitro, lithium reduces lymphocyte proliferation but also inhibits their apoptosis (32). Additionally, lymphocyte function in response to various stimuli is enhanced following exposure to lithium. Little is known about the mechanistic basis of these effects. It is currently controversial whether primarily GSK3 $\beta$, or other lithium targets account for the effects of lithium on lymphocytes.

\section{INHIBITION OF GSK3 ENHANCES CO-STIMULATION DURING ANTIGEN PRESENTATION}

Naïve helper (CD4 positive) $\mathrm{T}$ lymphocytes and to a lesser extent, naïve CTLs (CD8 positive) require three signals for their activation by APCs. TCR binding to peptide presented by the MHC II complex on an APC provides signal 1, whereas signal 2 requires binding of $\mathrm{CD} 28$ expressed in the $\mathrm{T}$ lymphocyte to B7-1 and B7-2 expressed in the APC $(33,34)$. Cytokines provide signal 3. Although CD28 was originally described as the main co-stimulation molecule in the immunological synapse, other molecules exist and are grouped in two main families, the immunoglobulin like (Ig-like) and tumor necrosis factor receptor like (TNFR-like) (35). Some members of the families like CD28 deliver stimulatory while others, like CTLA-4 deliver inhibitory signals (35).

CD28 signals primarily through the PI3K/AKT pathway and when activated, this axis suppresses GSK3 (Figure 2B) $(36,37)$. Interestingly, inhibition of GSK3 substitutes for CD28 activation in enhancing T cell proliferation (38). Mechanistically, GSK3 is constitutively active, phosphorylates NFAT transcription factors and enhances NFAT nuclear export (Figure 2A) (39). CD28 activation phosphorylates and inactivates GSK3, hence NFAT enters the nucleus in a de-phosphorylated state and induces $\mathrm{T}$ cell proliferation. In addition to enhancing NFAT nuclear translocation, GSK3 inhibition augments binding of NFAT2 to DNA (40). Alternatively, PI3K/AKT activation by CD28 


\section{A WNT pathway regulation}

WNT pathway OFF

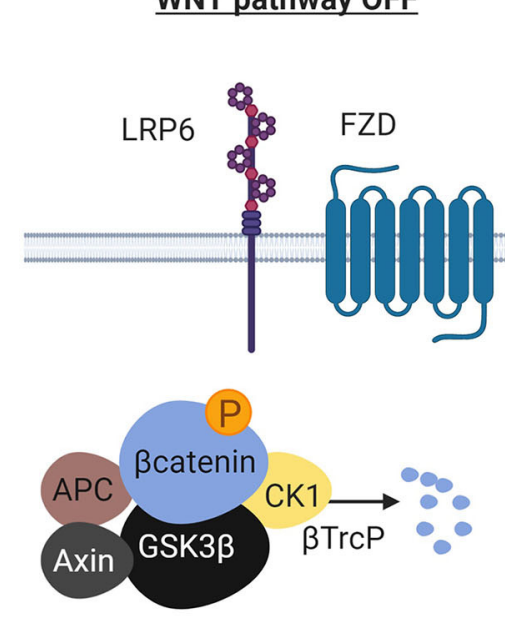

Bcatenin degradation
WNT pathway ON

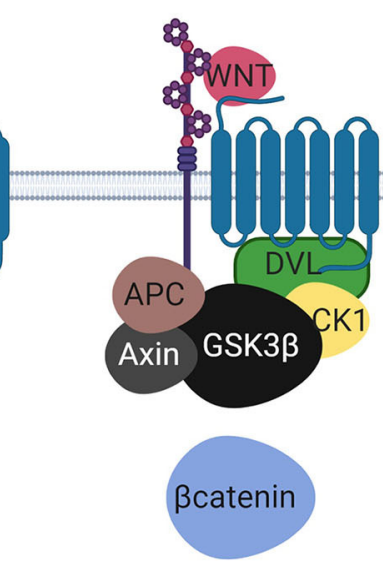

$\beta$ catenin

nuclear translocation
B Hormone receptor regulation

\author{
Insulin Receptor
}

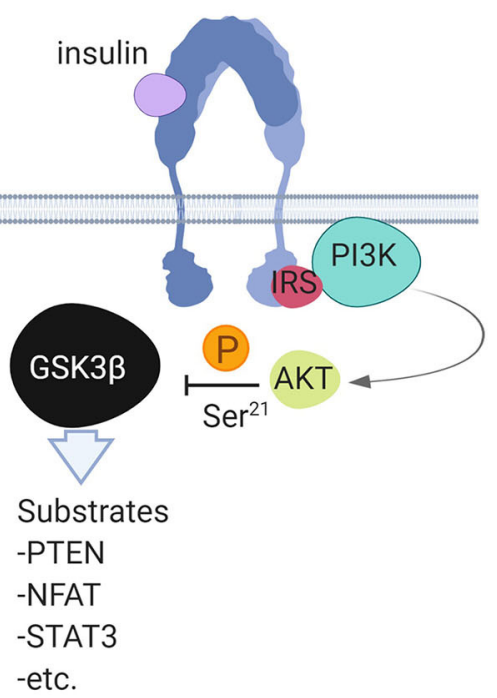

FIGURE 1 | Description of the GSK3 $\beta$ to regulate the WNT pathway and the Receptor Tyrosine Kinase pathway illustrated here by the insulin receptor. In (A), in the absence of WNT ligands (left), the scaffolding protein Axin forms a complex with beta catenin, Adenomatous Polyposis Coli (APC), GSK3 $\beta$ and Casein Kinase 1 (CK1). GSK3 $\beta$ phosphorylates beta catenin in the complex and ubiquitination by the ubiquitin ligase $\beta$ TrcP follows. Ubiquitinated beta catenin is then degraded by the proteasome. In the presence of WNT ligands (right), the WNT receptors Low Density Lipoprotein Receptor related protein 6 (LRP6) and Frizzled (FZD) recruit Disheveled (DVL) that binds to the complex and separates beta catenin. Beta catenin in this condition translocates to the nucleus to activate WNT responsive genes. In (B), the insulin receptor (other RTKs also), activates the PI3K/AKT pathway in the presence of insulin. AKT negatively regulates GSK3 $\beta$ by phosphorylating GSK3 $\beta$ at Ser-21. GSK3 $\beta$ in this cellular pool is constitutively active and is inactivated in the presence of growth factors. Created with BioRender.

activation/GSK3 $\beta$ inhibition and concurrent MAPK activation by TCR, are required to reduce the levels of $\mathrm{p} 27^{\mathrm{kip} 1}$, a negative cell cycle modulator. The net effect is hyperphosphorylation of retinoblastoma protein, progression of cell cycle and proliferation of primary T lymphocytes (36). Beyond NFAT and p27 kip1 CBLB, an E3 ubiquitin ligase with known inhibitory role in $\mathrm{T}$ cell activation, is a GSK3 substrate (41). Inactivation of GSK3 leads to reduced levels of Cbl-b and enhancement of T cell activation and autoimmunity in murine models (Figure 2B). The central role of GSK3 downstream of CD28 is also impactful in the immune tumor microenvironment. In a lymphoma model, Taylor et al. showed that GSK3 inhibition substitutes for CD28 activation and suppresses the PD1 axis (38).

GSK3 $\beta$ inhibition causes NFAT2 to accumulate in the nucleus of $\mathrm{T}$ cells and increase proliferation of $\mathrm{T}$ cells as well as to support maximal interleukin 2 production (42). Particularly, inactivation of GSK3 $\beta$ by the GTPase of immunity-associated protein 5 (GIMAP5) increases proliferation of CD4+T cells in autoimmune models (Figure 2B) (43). Conversely, Gattinoni et al. showed that GSK3 $\beta$ inhibition promotes the formation of a special population of $\mathrm{T}$ memory cells with stem cell properties (44). These cells have reduced proliferation rates and exert multipotency. Importantly, they expand fast and are more effective compared to other memory cell subsets when challenged by antigen and function against tumors.

\section{GSK3 $\beta$ REGULATES THE PD1/PDL1 AXIS IN CANCER CELLS INTERACTING WITH T EFFECTOR LYMPHOCYTES}

Tumor cells express PDL1 in their cell surface which interacts with PD1 in CD8 positive T cells $(45,46)$. The PD1/PDL1 axis causes $\mathrm{T}$ cell exhaustion and is a mechanism of immune escape for tumors. Interestingly, PD1 expression defines the population of tumor reactive CD8 positive $\mathrm{T}$ lymphocytes with neoantigen specificity (45). Exhausted T cells retain some anti-tumor activity but do not control tumors efficiently. The benefit of drugs with anti-PD1 and anti-PDL1 activity in a subgroup of patients with a range of malignancies highlights the importance of this molecular checkpoint (47).

PDL1 is a substrate for GSK3 $\beta$. This interaction leads to a number of phosphorylation steps and finally ubiquitination and proteasome degradation of PD-L1 (Figure 2C) (48). In the presence of growth factors, like Epidermal Growth Factor, AKT phosphorylates and inactivates GSK3 $\beta$. In these conditions, GSK3 $\beta$ no longer phosphorylates PDL1 and the levels of the latter molecule rise in the cancer cell. Additionally, Nglycosylation of PDL1 further protects PDL1 from GSK3 $\beta$ dependent phosphorylation in breast cancer, melanoma and colon cancer models (19). Conversely, on the CD8 positive T cell, GSK $3 \alpha / \beta$ induces the transcription of $p d c d 1$ that codes 

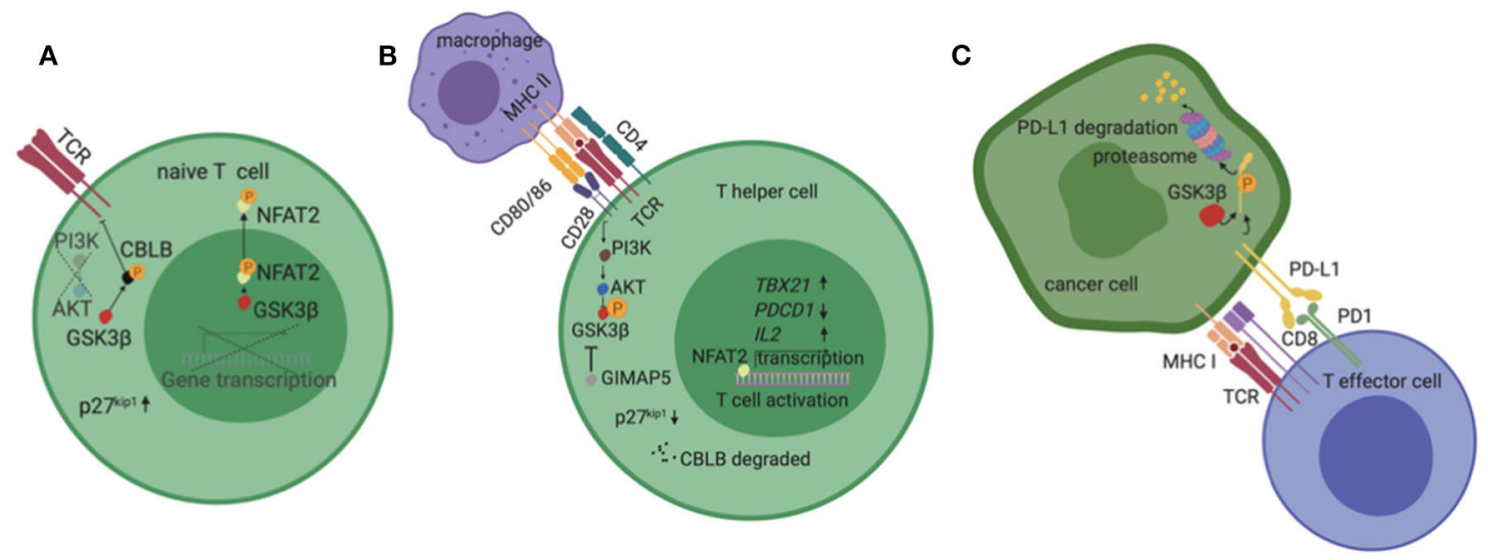

D Immunogenic effects

Immunosuppresive effects
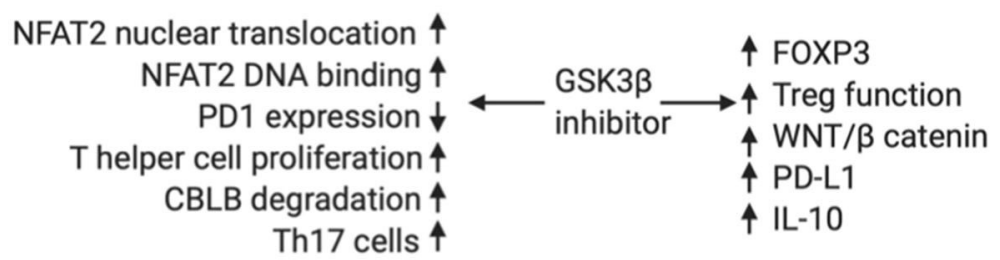

FIGURE 2 | (A) In the absence of co-stimulation, typically in a T lymphocyte that has not been exposed to antigen yet (naive T cell), GSK3 $\beta$ is constitutively active and phosphorylates NFAT2. Phosphorylated NFAT2 exits the nucleus and does not induce expression of target genes. Additionally, GSK3 $\beta$ phosphorylates CBLB, an inhibitor of TCR. Phosphorylated CBLB is protected from degradation. (B) In the presence of co-stimulation, typically when an APC presents a peptide to a CD4+ T cell, the second signal initiated by CD28 activates the PI3K/AKT pathway which phosphorylates and inactivates GSK3 $\beta$. In these conditions, NFAT2 is not phosphorylated, enters the nucleus and induces transcription of genes like TBX21 and IL2 which promote T cell activation and proliferation. Also, CBLB is degraded in a de-phosphorylated state and no longer inhibits TCR. Finally, the GTPase GIMAP5 can independently inhibit GSK3 $\beta$. (C) PD-L1 is phosphorylated by GSK3 $\beta$ and marked for degradation in the proteasome of cancer cells. (D) Summary of GSK3 $\beta$ inhibitor effects in the tumor immune microenvironment highlighting both immunogenic and immunosuppressive possibilities. Created with BioRender.

for murine PD1 in murine melanoma and lymphoma models (49). Interestingly, ex vivo inhibition of GSK $3 \alpha / \beta$ enhances the efficacy of adoptive $\mathrm{T}$ cell transfer in these models mirroring PD1 inhibition (49).

\section{TH17 POLARIZATION DEPENDS ON GSK3 $\beta$}

The discovery of Th17 subset of CD4+ T lymphocytes, distinct from Th1 and Th2 cells was followed by exploration of their role in the tumor microenvironment (50). Th17 cells originate from naive CD4+ T cells that are exposed to TGF $\beta$ and IL6 or IL23, express the RAR orphan receptor gamma (ROR $\gamma$ ) transcription factor and secrete IL17A, IL17F, IL21, IL22, and IL23. Additionally, Th17 cells can both originate from and also transform to Treg cells in a process known as Th17-Treg plasticity. Importantly, Th17 cells promote tumor growth in some models, while in others the effect is inhibitory. Dependence on context partially explains the Th17 paradox with TGF $\beta$ inducing an immunosuppressive, whereas IL23 an inflammatory phenotype on Th17 cells (51).

Polarization of CD4+ T cells into Th17 cells depends on active GSK3 $\beta$ in vitro and in vivo (52). Intriguingly, Th17 cells have 10-fold higher levels of GSK3 $\beta$ compared to other types of cells. Mechanistically, inhibition of GSK3 prevents IL6 production as well as STAT3 activation which are necessary steps for generation of Th17 cells. In disease models of F. tularensis pneumonia and experimental autoimmune encephalomyelitis (EAE), inhibition of GSK3 $\beta$ with lithium reduces the numbers of IL17A+CD4+ and IFN $\gamma+\mathrm{CD} 4+$ but spares Tregs in the lungs and spinal cords of mice, respectively. In both models, disease requires functional Th17 cells. In the EAE model, pre-treatment with lithium prevents development of the autoimmune phenotype and treatment of established EAE attenuates severity of symptoms. Notably, recruitment of CD8+ cells was reduced in the EAE model but was not affected in the $F$. tularensis pneumonia model. The role of GSK $3 \beta$ inhibition in Th17 cells in the tumor microenvironment is less well-studied.

\section{GSK3 $\beta$ INHIBITION ENHANCES TREG FUNCTION}

Tregs are important negative regulators of the adaptive immune response; they prevent autoimmune disease and maintain homeostasis $(9,10)$. They express CD4 and CD25, the high 
affinity receptor for interleukin 2 (IL-2). They also express the cytotoxic T-lymphocyte associated protein 4 (CTLA4) which binds to and induces endocytosis of B7-1 and B7-2, thereby antagonizes CD28 and blocks antigen presentation (9). The forkhead box P3 (FOXP3) transcription factor induces the expression of genes that promote Treg stability and immune suppressive function. GSK $3 \alpha / \beta$ is among the genes identified as positive regulators of FOXP3 in an siRNA screen (53). Interestingly, pharmacological inhibition of GSK3 $\beta$ in Tregs enhances their suppressive function and limits the turnover of FOXP3 (53). GSK3 $\beta$ inhibition enhances the survival of islet transplant in vivo (54). Although this was shown with one inhibitor only, results are intriguing as they point out a possible immunosuppressive effect of GSK3 $\beta$ inhibitors in the tumor microenvironment.

\section{WNT/ $\beta$ CATENIN AND PI3K/AKT PATHWAYS ARE ASSOCIATED WITH COLD TUMORS}

In a landmark study, Spranger et al. reported that the WNT/ $\beta$ catenin pathway is inversely correlated with $\mathrm{T}$ cell infiltration in melanoma tumors (55). The association was subsequently shown to occur in bladder cancer as well (4). Mechanistically, stabilization of $\beta$ catenin and binding of the latter to the ATF3 promoter inhibits CCL4 expression. The chemokine CCL4, along with CCL3, CXCL1, and CXCL2 are ligands for the receptor CCR5 found in the cell surface of BATF3 positive dendritic cells. Activation of WNT/ $\beta$ catenin pathway inhibits the expression of these chemokines and prevents BATF3 positive dendritic cells from infiltrating the tumor $(4,55)$. In the absence of dendritic cells, CD8 positive $\mathrm{T}$ lymphocytes also fail to migrate in the tumor resulting in a "cold" or non-inflamed tumor microenvironment. Likewise, PTEN loss and PI3K/AKT pathway activation induce CCL2 and VEGF expression and inhibit infiltration of $\mathrm{T}$ lymphocytes in melanoma tumors (56). Although these studies did not look into the role of GSK3 $\beta$ directly, it is noteworthy that both WNTt/ $\beta$ catenin and PI3K/AKT pathways are activated by GSK3 $\beta$ inhibition.

Additionally, inhibition of GSK3 $\beta$ reduces interleukin 6 (IL-6) and increases interleukin 10 (IL-10) levels in lipopolysaccharide models of inflammation (57-59). IL-6 mediates an inflammatory reaction in the tumor microenvironment while IL-10 is

\section{REFERENCES}

1. Schumacher TN, Scheper W, Kvistborg P. Cancer neoantigens. Annu Rev Immunol. (2019) 37:173-200. doi: 10.1146/annurev-immunol-042617-053402

2. Hanahan D, Weinberg RA. Hallmarks of cancer: the next generation. Cell. (2011) 144:646-74. doi: 10.1016/j.cell.2011.02.013

3. Schreiber RD, Old LJ, Smyth MJ. Cancer immunoediting: integrating immunity's roles in cancer suppression and promotion. Science. (2011) 331:1565-70. doi: 10.1126/science. 1203486

4. Spranger S. Mechanisms of tumor escape in the context of the T-cell-inflamed and the non-T-cell-inflamed tumor microenvironment. Int Immunol. (2016) 28:383-91. doi: 10.1093/intimm/dxw014 immunosuppressive and associated with an M2 macrophage profile. Importantly, GSK3 $\beta$ inhibition in memory $\mathrm{T}$ cells induces IL-10 levels, while the effect on proliferation is minimal compared to naïve T cells. In this context, memory T cells adopt a regulatory/immunosuppressive role, as supernatants from memory $\mathrm{T}$ cell cultures with prior inhibition of GSK3 $\beta$, limit the proliferation of receptor T lymphocytes in a IL-10 dependent fashion (58). Collectively, these data illustrate the multifaceted effects of GSK3 $\beta$ on the immune system as potentially both promoting and suppressing aspects of anti-tumor immunity.

\section{DISCUSSION}

A growing body of literature supports a multifaceted role for GSK3 $\beta$ in the immune tumor microenvironment. This is not a surprise as GSK3 $\beta$ is the busiest kinase in the cell based on the number of known and predicted substrates, many of which are key regulators of the immune response to tumors. Publication bias exists to some degree as there are either reports of GSK3 $\beta$ inhibitors as positive regulators of the immune response against tumors or negative regulators of the immune response in autoimmune conditions. In both contexts, GSK3 $\beta$ inhibitors are suggested as putative treatments. Both suppressing and enhancing immunity functions are possible for GSK3 $\beta$. In fact, this has been shown in diverse models and comes as no surprise given the diversity of GSK3 $\beta$ substrates. Figure 2D summarizes the possible effects of GSK3 $\beta$ inhibitors on the immune system in the tumor microenvironment.

With this is mind, it is difficult to predict whether clinical GSK3 $\beta$ inhibition will enhance or suppress immunity against tumors. Further study of GSK3 $\beta$ regulation is required to define the context where GSK3 $\beta$ can be beneficial and support design of more precise drugs, such that target pro-tumorigenic while sparing the anti-tumorigenic functions of GSK3 $\beta$.

\section{AUTHOR CONTRIBUTIONS}

$\mathrm{AD}$ and KS have contributed to the conception or design of the work as well as the acquisition, analysis or interpretation of studies included in this review. AD has drafted and KS revised the manuscript. Both authors approve publication of the content and agree to be accountable for all aspects of the work in ensuring that questions related to the accuracy or integrity of any part of the work are appropriately investigated and resolved. 
9. Chaudhary B, Elkord E. Regulatory T cells in the tumor microenvironment and cancer progression: role and therapeutic targeting. Vaccines. (2016) 4:28. doi: $10.3390 /$ vaccines 4030028

10. Zhu J, Paul WE. CD4 T cells: fates, functions, and faults. Blood. (2008) 112:1557-69. doi: 10.1182/blood-2008-05-078154

11. Parker DC. T cell-dependent B cell activation. Annu Rev Immunol. (1993) 11:331-60. doi: 10.1146/annurev.iy.11.040193.001555

12. Parker DC. The functions of antigen recognition in $\mathrm{T}$ cell-dependent $\mathrm{B}$ cell activation. Semin Immunol. (1993) 5:413-20. doi: 10.1006/smim.1993.1047

13. Ekkens MJ, Shedlock DJ, Jung E, Troy A, Pearce EL, Shen H, et al. Th1 and Th2 cells help CD8 T-cell responses. Infect Immun. (2007) 75:22916. doi: 10.1128/IAI.01328-06

14. Takeuchi A, Saito T. CD4 CTL, a cytotoxic subset of CD4(+) T cells, their differentiation and function. Front Immunol. (2017) 8:194. doi: 10.3389/fimmu.2017.00194

15. Binnewies M, Roberts EW, Kersten K, Chan V, Fearon DF, Merad M, et al. Understanding the tumor immune microenvironment (TIME) for effective therapy. Nat Med. (2018) 24:541-50. doi: 10.1038/s41591-018-0014-x

16. Woodgett JR. Molecular cloning and expression of glycogen synthase kinase3/factor A. EMBO J. (1990) 9:2431-8. doi: 10.1002/j.1460-2075.1990.tb07419.x

17. Jope RS. Glycogen synthase kinase-3 in the etiology and treatment of mood disorders. Front Mol Neurosci. (2011) 4:16. doi: 10.3389/fnmol.2011.00016

18. Walz A, Ugolkov A, Chandra S, Kozikowski A, Carneiro BA, O'Halloran TV, et al. Molecular pathways: revisiting glycogen synthase kinase-3beta as a target for the treatment of cancer. Clin Cancer Res. (2017) 23:18917. doi: 10.1158/1078-0432.CCR-15-2240

19. Li CW, Lim SO, Xia W, Lee HH, Chan LC, Kuo CW, et al. Glycosylation and stabilization of programmed death ligand-1 suppresses T-cell activity. Nat Commun. (2016) 7:12632. doi: 10.1038/ncomms 12632

20. Beurel E, Grieco SF, Jope RS. Glycogen synthase kinase-3 (GSK3): regulation, actions, and diseases. Pharmacol Ther. (2015) 148:114-31. doi: 10.1016/j.pharmthera.2014.11.016

21. Cross DA, Alessi DR, Vandenheede JR, McDowell HE, Hundal HS, Cohen P. The inhibition of glycogen synthase kinase- 3 by insulin or insulin-like growth factor 1 in the rat skeletal muscle cell line L6 is blocked by wortmannin, but not by rapamycin: evidence that wortmannin blocks activation of the mitogen-activated protein kinase pathway in L6 cells between ras and raf. Biochem J. (1994) 303:21-6. doi: 10.1042/bj3030021

22. Wojtaszewski JF, Nielsen P, Kiens B, Richter EA. Regulation of glycogen synthase kinase- 3 in human skeletal muscle: effects of food intake and bicycle exercise. Diabetes. (2001) 50:265-9. doi: 10.2337/diabetes.50.2.265

23. Ding VW, Chen RH, McCormick F. Differential regulation of glycogen synthase kinase 3beta by insulin and Wnt signaling. J Biol Chem. (2000) 275:32475-81. doi: 10.1074/jbc.M005342200

24. Dajani R, Fraser E, Roe SM, Young N, Good V, Dale TC, et al. Crystal structure of glycogen synthase kinase 3 beta: structural basis for phosphateprimed substrate specificity and autoinhibition. Cell. (2001) 105:72132. doi: 10.1016/S0092-8674(01)00374-9

25. Fang X, Yu SX, Lu Y, Bast RC Jr, Mills GB. Phosphorylation and inactivation of glycogen synthase kinase 3 by protein kinase A. Proc Natl Acad Sci USA. (2000) 97:11960-5. doi: 10.1073/pnas.220413597

26. Wu D, Pan W. GSK3: a multifaceted kinase in wnt signaling. Trends Biochem Sci. (2010) 35:161-8. doi: 10.1016/j.tibs.2009.10.002

27. Lee HC, Tsai JN, Liao PY, Tsai WY, Lin KY, Chuang CC, et al. Glycogen synthase kinase 3 alpha and 3 beta have distinct functions during cardiogenesis of zebrafish embryo. BMC Dev Biol. (2007) 7:93. doi: 10.1186/1471-213X-7-93

28. Doble BW, Woodgett JR. GSK-3: tricks of the trade for a multi-tasking kinase. J Cell Sci. (2003) 116:1175-86. doi: 10.1242/jcs.00384

29. Maccario H, Perera NM, Davidson L, Downes CP, Leslie NR. PTEN is destabilized by phosphorylation on Thr366. Biochem J. (2007) 405:43944. doi: 10.1042/BJ20061837

30. Tisman G, Show-Jen GW. Haematological side-effects of lithium. In: Johnson FN, editor. Handbook of Lithium Therapy. Dordrecht: Springer (1980). p. 338-44.

31. Perez-Cruet J, Dancey JT. Thymus gland involution induced by lithium chloride. Experientia. (1977) 33:646-8. doi: 10.1007/BF01946552
32. Pietruczuk K, Lisowska KA, Grabowski K, Landowski J, Witkowski JM. Proliferation and apoptosis of T lymphocytes in patients with bipolar disorder. Sci Rep. (2018) 8:3327. doi: 10.1038/s41598-018-21769-0

33. Chen L, Flies DB. Molecular mechanisms of $\mathrm{T}$ cell co-stimulation and coinhibition. Nat Rev Immunol. (2013) 13:227-42. doi: 10.1038/nri3405

34. Diehn M, Alizadeh AA, Rando OJ, Liu CL, Stankunas K, Botstein D, et al. Genomic expression programs and the integration of the CD28 costimulatory signal in T cell activation. Proc Natl Acad Sci USA. (2002) 99:11796801. doi: 10.1073/pnas.092284399

35. Sharpe AH. Mechanisms of costimulation. Immunol Rev. (2009) 229:511. doi: $10.1111 / j .1600-065 X .2009 .00784 . x$

36. Appleman LJ, van Puijenbroek AA, Shu KM, Nadler LM, Boussiotis VA. CD28 costimulation mediates down-regulation of p27kipl and cell cycle progression by activation of the PI3K/PKB signaling pathway in primary human T cells. $J$ Immunol. (2002) 168:2729-36. doi: 10.4049/jimmunol.168.6.2729

37. Wood JE, Schneider H, Rudd CE. TcR and TcR-CD28 engagement of protein kinase $\mathrm{B}$ (PKB/AKT) and glycogen synthase kinase-3 (GSK-3) operates independently of guanine nucleotide exchange factor VAV-1. J Biol Chem. (2006) 281:32385-94. doi: 10.1074/jbc.M604878200

38. Taylor A, Rudd CE. Glycogen synthase kinase 3 inactivation compensates for the lack of $\mathrm{CD} 28$ in the priming of $\mathrm{CD} 8(+)$ cytotoxic T-cells: implications for anti-PD-1 immunotherapy. Front Immunol. (2017) 8:1653. doi: $10.3389 /$ fimmu. 2017.01653

39. Pan M, Winslow MM, Chen L, Kuo A, Felsher D, Crabtree GR. Enhanced NFATc1 nuclear occupancy causes $\mathrm{T}$ cell activation independent of CD28 costimulation. J Immunol. (2007) 178:431521. doi: 10.4049/jimmunol.178.7.4315

40. Neal JW, Clipstone NA. Glycogen synthase kinase-3 inhibits the DNA binding activity of NFATc. J Biol Chem. (2001) 276:3666-73. doi: 10.1074/jbc.M004888200

41. Tran CW, Saibil SD, Le Bihan T, Hamilton SR, Lang KS, You H, et al. Glycogen synthase kinase-3 modulates Cbl-b and constrains t cell activation. J Immunol. (2017) 199:4056-65. doi: 10.4049/jimmunol.1600396

42. Ohteki T, Parsons M, Zakarian A, Jones RG, Nguyen LT, Woodgett $\mathrm{JR}$, et al. Negative regulation of $\mathrm{T}$ cell proliferation and interleukin 2 production by the serine threonine kinase GSK-3. J Exp Med. (2000) 192:99104. doi: 10.1084/jem.192.1.99

43. Patterson AR, Endale M, Lampe K, Aksoylar HI, Flagg A, Woodgett JR, et al. Gimap5-dependent inactivation of GSK3beta is required for CD4(+) T cell homeostasis and prevention of immune pathology. Nat Commun. (2018) 9:430. doi: 10.1038/s41467-018-02897-7

44. Gattinoni L, Zhong XS, Palmer DC, Ji Y, Hinrichs CS, Yu Z, et al. Wnt signaling arrests effector $\mathrm{T}$ cell differentiation and generates $\mathrm{CD} 8+$ memory stem cells. Nat Med. (2009) 15:808-13. doi: 10.1038/nm.1982

45. Gros A, Robbins PF, Yao X, Li YF, Turcotte S, Tran E, et al. PD-1 identifies the patient-specific $\mathrm{CD} 8(+)$ tumor-reactive repertoire infiltrating human tumors. J Clin Invest. (2014) 124:2246-59. doi: 10.1172/JCI73639

46. Ostrand-Rosenberg S, Horn LA, Haile ST. The programmed death-1 immunesuppressive pathway: barrier to antitumor immunity. J Immunol. (2014) 193:3835-41. doi: 10.4049/jimmunol.1401572

47. Gong J, Chehrazi-Raffle A, Reddi S, Salgia R. Development of PD-1 and PDL1 inhibitors as a form of cancer immunotherapy: a comprehensive review of registration trials and future considerations. J Immunother Cancer. (2018) 6:8. doi: 10.1186/s40425-018-0316-z

48. Sengupta S, Katz SC, Sengupta S, Sampath P. Glycogen synthase kinase 3 inhibition lowers PD-1 expression, promotes long-term survival and memory generation in antigen-specific CAR-T cells. Cancer Lett. (2018) 433:1319. doi: 10.1016/j.canlet.2018.06.035

49. Taylor A, Rothstein D, Rudd CE. Small-molecule inhibition of PD-1 transcription is an effective alternative to antibody blockade in cancer therapy. Cancer Res. (2018) 78:706-17. doi: 10.1158/0008-5472.CAN17-0491

50. Zou W, Restifo NP. $\mathrm{T}(\mathrm{H}) 17$ cells in tumour immunity and immunotherapy. Nat Rev Immunol. (2010) 10:248-56. doi: 10.1038/nri2742

51. Bailey SR, Nelson MH, Himes RA, Li Z, Mehrotra S, Paulos CM. Th17 cells in cancer: the ultimate identity crisis. Front Immunol. (2014) 5:276. doi: $10.3389 /$ fimmu. 2014.00276 
52. Beurel E, Yeh WI, Michalek SM, Harrington LE, Jope RS. Glycogen synthase kinase- 3 is an early determinant in the differentiation of pathogenic Th17 cells. J Immunol. (2011) 186:1391-8. doi: 10.4049/jimmunol.1003511

53. Ding $M$, Brengdahl J, Lindqvist $M$, Gehrmann U, Ericson E, von Berg S, et al. A phenotypic screening approach using human treg cells identified regulators of forkhead box p3 expression. ACS Chem Biol. (2019) 14:54353. doi: 10.1021 /acschembio.9b00075

54. Graham JA, Fray M, de Haseth S, Lee KM, Lian MM, Chase CM, et al. Suppressive regulatory $\mathrm{T}$ cell activity is potentiated by glycogen synthase kinase 3 \{beta\} inhibition. J Biol Chem. (2010) 285:328529. doi: 10.1074/jbc.M110.150904

55. Spranger S, Bao R, Gajewski TF. Melanoma-intrinsic betacatenin signalling prevents anti-tumour immunity. Nature. (2015) 523:231-5. doi: 10.1038/nature14404

56. Peng W, Chen JQ, Liu C, Malu S, Creasy C, Tetzlaff MT, et al. Loss of PTEN promotes resistance to $\mathrm{T}$ cell-mediated immunotherapy. Cancer Discov. (2016) 6:202-16. doi: 10.1158/1538-7445.AM20 $16-4363$

57. Beurel E, Jope RS. Lipopolysaccharide-induced interleukin-6 production is controlled by glycogen synthase kinase- 3 and STAT3 in the brain. $J$ Neuroinflammation. (2009) 6:9. doi: 10.1186/1742-2094-6-9
58. Garcia CA, Benakanakere MR, Alard P, Kosiewicz MM, Kinane DF, Martin M. Antigenic experience dictates functional role of glycogen synthase kinase-3 in human CD4+ T cell responses. J Immunol. (2008) 181:836371. doi: 10.4049/jimmunol.181.12.8363

59. Wang H, Brown J, Garcia CA, Tang Y, Benakanakere MR, Greenway T, et al. The role of glycogen synthase kinase 3 in regulating IFN-beta-mediated IL-10 production. J Immunol. (2011) 186:675-84. doi: 10.4049/jimmunol.1001473

Conflict of Interest: $\mathrm{AD}$ has received honoraria by Roche/Genentech for a non-CME educational activity, not related to the content of this review.

The remaining author declares that the research was conducted in the absence of any commercial or financial relationships that could be construed as a potential conflict of interest.

Copyright $\odot 2020$ Dimou and Syrigos. This is an open-access article distributed under the terms of the Creative Commons Attribution License (CC BY). The use, distribution or reproduction in other forums is permitted, provided the original author(s) and the copyright owner(s) are credited and that the original publication in this journal is cited, in accordance with accepted academic practice. No use, distribution or reproduction is permitted which does not comply with these terms. 